\title{
ACUMULAÇÃO FLEXÍVEL E PARADIGMA GERENCIAL: OS IMPACTOS NA QUALIFICAÇÃO DOS TÉCNICOS DE ENFERMAGEM NOS ANOS 2000
}

\author{
FLEXIBLE ACCUMULATION AND MANAGEMENT PARADIGM:THE IMPACTS ON QUALIFICATION \\ OF NURSE TECHNICIAN IN THE 2000S
}

\author{
ACUMULACÍON FLEXIBLE Y PARADIGMA GERENCIAL: LOS IMPACTOS EN LA CUALIFICACIÓN DE \\ TÉCNICOS DE ENFERMERÍA EN LOS AÑOS 2000
}

Roberta de Carvalho Corôa ${ }^{1}$

Resumo Neste artigo, identifico as determinações políticas e sociais que perpassam a gestão do trabalho no Sistema Único de Saúde durante os anos 2000 e discuto a configuração da qualificação do trabalho dos técnicos de enfermagem com base em documentos oficiais do período. O trabalho no Sistema Único de Saúde, nas últimas duas décadas, foi perpassado por dois movimentos centrais: ideias de gestão adotadas pelo Estado relacionadas ao paradigma da administração pública gerencial; e articulação das especificidades do trabalho em saúde, a um só tempo, com os princípios e diretrizes definidos para o sistema na Constituição Federal de 1988 e com os modos de organização do trabalho característicos do padrão de acumulação flexível. A conformação desses elementos, por sua vez, se expressa nas ações e programas do Ministério da Saúde como novas demandas para o trabalho em saúde, que dão ênfase aos aspectos subjetivos, emocionais e relacionais da atividade.

Palavras-chave trabalho em saúde; técnicos de enfermagem; qualificação do trabalho em saúde; gestão do trabalho em saúde.
Abstract In this article, we identify the political and social determinations that underlie the work of management in the Brazilian Unified Health System during the 2000s and discuss the configurations of the qualification of nurse technicians based on official documents of the period. The work on the National Health System, in the last two decades, was permeated by two central movements: management ideas adopted by the State related to the paradigm of public administration management; and articulation of the specificities of the health work, at the same time, with the principles and guidelines defined by the Federal Constitution of 1988 and with the ways of organizing work characteristic of flexible accumulation pattern. The shape of these elements, in turn, is expressed in the actions and the Ministry of Health programs as new demands for health work, which give emphasis to the subjective, emotional and relational aspects of activity.

Keywords health work; nurse technicians; qualification of health work; health work management. 


\section{Introdução}

Neste artigo, identifico as determinações políticas e sociais que perpassam a gestão do trabalho no Sistema Único de Saúde (SUS) durante os anos 2000 e discuto a configuração da qualificação do trabalho dos técnicos de enfermagem com base em documentos oficiais do período. A criação da Secretaria de Gestão do Trabalho e da Educação na Saúde (SGTES) no ano de 2003 foi tomada como marco político do processo. Recebeu destaque na análise a Política Nacional de Humanização (HumanizaSUS), que ganha força no período como uma política transversal e que propõe uma nova cultura relacional entre os atores do sistema envolvidos no cuidado (gestores, trabalhadores e usuários), e a Política Nacional de Educação Permanente em Saúde (Pneps), que traz uma nova concepção de formação para os trabalhadores do SUS.

Parte-se do pressuposto de que as formas assumidas pelo trabalho no setor saúde só podem ser compreendidas em sua complexidade quando postas em conexão com a totalidade das relações sociais no sistema capitalista. Dessa forma, busco relacionar as transformações propostas pela gestão e a reconfiguração da qualificação dos técnicos em enfermagem aos movimentos mais gerais de articulação entre capital, trabalho e Estado na sociedade contemporânea.

O conceito de 'qualificação do trabalho', por sua vez, é compreendido em sua perspectiva relativista. ${ }^{2}$ Nessa concepção, a qualificação é definida, ao mesmo tempo, como processo e produto social. Para além do prisma da técnica e do conteúdo do trabalho, afirma-se que a qualificação decorre das negociações tensas entre capital e trabalho, e de fatores socioculturais, que influenciam o julgamento e a classificação que a sociedade faz sobre os indivíduos (Tartuce, 2004).

$\mathrm{O}$ argumento defendido neste artigo é que o trabalho no SUS, nas duas últimas décadas, foi perpassado por dois movimentos centrais: ideias de gestão adotadas pelo Estado relacionadas ao paradigma da administração pública gerencial (Bresser-Pereira, 1996; Brasil, 1995); e articulação das especificidades do trabalho em saúde, a um só tempo, com os princípios e diretrizes definidos para o sistema na Constituição Federal de 1988 e com os modos de organização do trabalho característicos do padrão de acumulação flexível.

A conformação desses elementos, por sua vez, se expressa nas ações e programas do Ministério da Saúde sob a forma de novas demandas para o trabalho em saúde, que dão ênfase aos aspectos subjetivos, emocionais e relacionais da atividade. Nesse sentido, nos anos 2000, com a finalidade de completar a efetivação do SUS e reafirmar os princípios e diretrizes do sistema, a HumanizaSUS mobiliza em seu texto as categorias de vínculo e aco- 
lhimento com os usuários, a ênfase na realização do trabalho em equipe e a responsabilização dos trabalhadores pela qualidade dos serviços prestados pelo sistema, enquanto a Pneps elege o cotidiano dos serviços de saúde como o local privilegiado para a formação e a qualificação dos trabalhadores.

O olhar sobre a construção social da qualificação dos técnicos de enfermagem revela que, historicamente, ela tem sido delineada por aspectos relacionados à divisão sexual e à divisão social e técnica do trabalho. $\mathrm{O}$ fato se expressa no cotidiano dos serviços mediante relações de poder bem marcadas entre as hierarquias profissionais, pelo caráter parcelarizado e delegado das atividades realizadas por esses trabalhadores e pela desvalorização do trabalho de cuidado, materializada nos baixos salários. Assim, é possível afirmar que essa dimensão social da qualificação constitui, em si, um desafio à nova cultura relacional almejada pela política de gestão do trabalho que vai ser desenhada para o sistema. Ao mesmo tempo, verifica-se uma situação em que a qualificação pode reconfigurar-se, tendo como ponto de partida as novas dinâmicas assumidas pelos atores no SUS.

$\mathrm{O}$ artigo permite uma reflexão acerca dos limites impostos pela sociedade capitalista, e pela própria estrutura do SUS, às mudanças na organização do trabalho em saúde e nas relações de poder a que estão submetidos os técnicos de enfermagem. Uma vez identificadas as determinações sociais e políticas que perpassam a gestão do trabalho no SUS, fica evidente que as ações e programas empreendidos pelo Ministério da Saúde nos anos 2000 são influenciados e se apropriam dos ideários de gestão oriundos do novo paradigma produtivo e da concepção de Estado que o resguarda.

Por conseguinte, se a implantação das ações que visam transformar a realidade do trabalho nos serviços de saúde não for acompanhada de reparos estruturais dentro do sistema - como estratégias de desprecarização do trabalho e de valorização profissional -, corre-se o risco de que o empoderamento e a autonomia propostos se configurem em mais um instrumento de responsabilização e mobilização subjetiva dos trabalhadores - elementos esses que dão continuidade às situações de exploração do trabalho no capitalismo contemporâneo.

\section{O Sistema Único de Saúde}

O SUS foi instituído pela Constituição Federal de 1988 e, trazendo a saúde como direito universal e dever do Estado brasileiro, é reconhecido como uma das maiores conquistas sociais já alcançadas no país. O projeto que lhe deu origem vinha sendo discutido pelo Movimento Sanitário desde a década de 1970. Para além de uma reforma setorial, o conjunto de propostas representava o ensejo por um novo modelo de sociedade. Na lei 
que marca a sua criação (Brasil, 1988), foram definidos como princípios a universalidade - garantindo direito à saúde a todos os brasileiros; a equidade - cada indivíduo deve receber igualmente a atenção em saúde necessária; e a integralidade os diferentes níveis de atenção se comunicam e formam uma rede de serviços integrada. Para a efetivação desses princípios, deveriam ser adotadas as diretrizes de descentralização, hierarquização e participação social.

No plano político internacional, o momento histórico da criação do SUS foi marcado pela existência de um projeto neoliberal, que supôs ajustes nos níveis macro e microeconômicos. Apesar das propostas originais do Movimento Sanitário defenderem a universalização do direito à saúde sob controle e responsabilidade exclusivos do Estado, o sistema já nasceu juridicamente aberto à participação da iniciativa privada, ainda que em caráter complementar.

\section{A década de 1990 e o trabalho no SUS}

Na década posterior à sua criação, o recém-criado Sistema Único de Saúde teve seus princípios e diretrizes perpassados por determinações advindas do modelo da administração pública gerencial, o que configurou nos anos seguintes a apropriação das especificidades do trabalho e da gestão no sistema pelo paradigma gerencial da empresa contemporânea.

A nova forma de administração pública3 teve origem, sobretudo, na GrãBretanha e nos Estados Unidos, e surge como uma alternativa tanto ao modelo estatal tradicional burocrático característico da sociedade fordista quanto ao neoliberalismo desenfreado que causara danos sociais perversos. O fenômeno é expressão de uma nova conjuntura na relação entre Estado, mercado e sociedade, e possui interface com o projeto político da Terceira Via (Giddens, 1995) e com as novas formas de gerir e organizar o trabalho e a empresa no capitalismo contemporâneo.

No Brasil, a chegada da nova administração pública teve comomarco político a Reforma Gerencial Brasileira (Bresser-Pereira, 1996), empreendida no ano de 1995, no contexto do governo de Fernando Henrique Cardoso (1995-2002). Na ocasião, o diagnóstico era de uma crise administrativa no Estado. Entre as causas do problema, foram citadas a crise fiscal, o esgotamento da estratégia estatizante e a necessidade de se alcançar uma administração pública democrática. As reformas pretendidas foram sistematizadas no documento "Plano Diretor da Reforma do Aparelho de Estado" (Brasil, 1995) e sinalizavam a necessidade de uma administração pública mais flexível e eficiente, pautada nos conceitos de qualidade e produtividade. Para tal, era condição a descentralização, com a ideia de que a gestão e a produção dos serviços estivessem cada vez mais próximas e voltadas para o cidadão-cliente, possibilitando o controle social e o desenvolvimento da cidadania. 
Dentre as ações empreendidas na busca por eficiência e produtividade, o Regime Jurídico Único e o princípio de isonomia nos serviços públicos foram extintos, e houve flexibilização da estabilidade dos servidores, com a possibilidade de demissões por insuficiência ou por excesso de quadros (Teixeira, Oliveira e Arantes, 2012). No que tange ao processo de descentralização, foram expandidas as formas de publicização da gestão, caracterizadas pela transferência da gestão de serviços e atividades, antes de responsabilidade do Estado, para o setor público não estatal, conferindo caráter público a entidades de direito privado, bem como autonomia administrativa e financeira.

No setor saúde, as políticas governamentais foram suscetíveis às recomendações das agências de financiamento internacionais, e é nesse contexto que a Organização Pan-Americana de Saúde (Opas) publica, no ano de 1994, uma coletânea, compatível com as recomendações do Banco Mundial e do Fundo Monetário Internacional (FMI), com o título “Perspectivas para a gestão do trabalho no Sistema Único de Saúde" .. ${ }^{4}$ Com isso, foram operadas transformações principalmente no sentido da flexibilização das relações de trabalho e do próprio SUS. O processo de descentralização nos moldes gerenciais, em combinação com necessidade de expansão dos serviços de saúde impulsionada pela criação do SUS e pela reorientação do modelo assistencial, gerou a vinculação de novos trabalhadores ao sistema por intermédio de formas atípicas e, por vezes, ilegais de contratação (Varella e Pierantoni, 2008).

Nesse sentido, a década de 1990 é classificada por estudiosos do tema como um período de grandes perdas no caminho para a efetivação do Sistema Único de Saúde brasileiro (Machado, 2009; Lima, 2010; Chinelli, Lacerda e Vieira, 2011, por exemplo). Apesar de não ter havido redução dos postos de trabalho, fato justificável pela indispensabilidade do trabalho vivo em ato na realização do trabalho de cuidado (Deddeca, 2008), a reforma gerencial do Estado se expressou de forma negativa nos serviços públicos de saúde. Como principal consequência está a parceria entre o público e o privado que, viabilizada pelos processos de flexibilização das relações de trabalho, terceirização de atividades e legalização de novos arranjos institucionais, ocasionou, em muitos casos, perda de direitos para os trabalhadores.

Para além dos aspectos técnico-administrativos da reforma, uma segunda ordem de fatores é relevante para discutir a configuração da qualificação dos técnicos de enfermagem em nível institucional. O plano diretor apresentado pelo Governo Federal declaradamente comportava uma dimensão cultural. Paralelamente às mudanças nos arranjos da gestão, buscava-se alcançar uma nova cultura no interior das organizações: seriam novas formas de trabalhar no serviço público, embasadas em novos valores e comportamentos. Os princípios da qualidade e da participação cumpririam papel estratégico no processo de transformação, e o Programa da Qualidade e da 
Participação na Administração Pública (Brasil, 1997) trazia como orientações o incentivo à criatividade e ao desenvolvimento de um espírito empreendedor no serviço público; a gestão participativa, existindo cooperação entre administradores e funcionários e participação desses últimos na definição dos processos de trabalho; a existência de capacitação permanente para o servidor; e a elaboração de iniciativas a fim de reforçar o sentido de missão no serviço público.

Simultaneamente ao processo, expandiam-se no país novas formas de organizar e gerir o trabalho, oriundas do movimento de 'reestruturação produtiva'. O fenômeno que atingiu os países desenvolvidos no final dos anos 1970, identificado com o desmantelamento das relações sólidas de emprego características do modelo fordista e com a incorporação de novas tecnologias ao processo de trabalho, chega ao Brasil de forma significativa nos anos 1990. As transformações que de início ganharam visibilidade nas esteiras das indústrias, com o crescimento em massa do desemprego estrutural e dos impactos negativos na organização sindical e nos direitos sociais, não tardaram muito a se expandir para espaços de produção de bens sociais estatais. Na área da saúde não houve redução dos postos de trabalho; no entanto, estudos já mostraram que a introdução de novas tecnologias intensificou o ritmo e a tensão contida nas atividades (Pires, 2008).

No que tange às especificidades do setor, mudanças de outra natureza também foram realizadas nos modos de organização do trabalho em saúde. Desde a Reforma Sanitária, o país passava por uma reorientação do modelo assistencial, que pressupunha o deslocamento do modelo hospitalar para uma concepção ampliada de saúde, em que ela aparece como resultado de determinantes sociais. Nessa perspectiva, os serviços, bem como seus trabalhadores, deveriam aproximar-se das condições de vida da população atendida. Como consequência, progressivamente passaram a ser valorizadas as tecnologias leves - aquelas ditas relacionais - do processo de trabalho em saúde, que a partir dos anos 2000 serão consideradas centrais para a qualidade da atenção prestada pelo SUS (Merhy e Franco, 2009).

\section{A criação da SGTES e a materialização de uma política de gestão do trabalho para o Sistema Único de Saúde}

A preocupação com os problemas referentes à gestão do trabalho e da educação na saúde perpassa toda a história do SUS. Dois anos antes da sua criação, o relatório da I Conferência Nacional de Recursos Humanos em Saúde (CNRHS), realizada no ano de 1986, já sinalizava os problemas com a gestão da força de trabalho que o sistema teria pela frente. A agenda formulada trouxe expressas reivindicações de trabalhadores e gestores, e 
ressaltou os obstáculos relativos à baixa qualificação profissional, à baixa remuneração dos trabalhadores, às condições de trabalho pouco favoráveis e à convivência de contratos de trabalho diferenciados no interior dos serviços (Brasil, 1986).

Os processos de descentralização empreendidos em meio à Reforma gerencial do Estado cuidaram de agravar esses problemas, como indica grande parte da literatura produzida sobre o período (Machado, 2009; Lima, 2010; Chinelli, Lacerda e Vieira, 2011; Martins e Molinaro, 2013). Assim, no ano de 2002, a Norma Operacional Básica de Recursos Humanos do SUS (NOB/RH-SUS) identificou problemas bem semelhantes àqueles que haviam estado na agenda da I CNRHS dezesseis anos antes. $\mathrm{O}$ documento assinala a baixa remuneração, a ausência de um plano de cargos, carreira e salários, a falta de regulação do trabalho e a multiplicidade de vínculos como os grandes problemas a serem enfrentados pelo Sistema Único de Saúde (Brasil, 2002). Ainda segundo o documento, esses fatores estariam comprometendo a valorização profissional e a fixação de profissionais nos serviços públicos de saúde, concorrendo para o comprometimento da qualidade dos procedimentos realizados.

Luiz Inácio Lula da Silva (2003-2010) assumiu a Presidência da República no ano 2003. O plano de governo apresentava uma proposta de revitalização do Estado. Dentre os principais objetivos, estavam a redução do déficit institucional, a melhoria da capacidade de formular e implantar políticas públicas e o incremento da participação, da transparência e da ética na administração pública. O fortalecimento da gestão foi apontado como medida fundamental para a resolução dos problemas enfrentados pelo país na área da saúde (Partido dos Trabalhadores, 2002), e tanto a gestão da força de trabalho quanto a gestão da educação em saúde foram consideradas estratégicas para a expansão e a melhoria da atenção prestada pelo sistema (Brasil, 2003 e 2004a).

O novo governo deu espaço no Ministério da Saúde a intelectuais e gestores que estiveram envolvidos na luta pela Reforma Sanitária brasileira, declarando-se o realinhamento com os princípios e diretrizes definidos constitucionalmente para o SUS (Brasil, 2003 e 2004a). Como parte do processo, firmou-se o compromisso do tratamento de questões relativas à força de trabalho em saúde, questões que, segundo o grupo que passa a ocupar o governo, estiveram ausentes dos cuidados do Estado no período anterior (Machado, 2009). Declarou-se então que a criação da Secretaria de Gestão do Trabalho e da Educação na Saúde era uma tentativa de quitar a dívida social do Estado brasileiro com o Sistema Único de Saúde, que data de suas origens e se agravou nos anos que se seguiram (Chinelli, Lopes e Vieira, 2011).

A SGTES, institucionalizada em 2003, surge subdivida em dois departamentos: Departamento de Gestão da Educação em Saúde (Deges) e Departa- 
mento de Gestão e Regulação do Trabalho em Saúde (Degerts). A agenda positiva do Degerts, datada do ano de 2004, materializa, em uma série de propostas e ações, a política de gestão do trabalho para a área da saúde vigente nos anos 2000. O momento representou, pela primeira vez na história do SUS, a existência de esforços unificados e coordenados para o tratamento das questões referentes ao trabalho e à educação dos trabalhadores de saúde. Até então, a gestão do trabalho era designada como área de recursos humanos, e encontrava-se a cargo de uma coordenação de terceiro escalão do Ministério da Saúde. Já as iniciativas para a formação dos trabalhadores passaram a ser desenvolvidas sob a forma de capacitações programáticas, específicas para cada área e distribuídas pelas secretarias (Teixeira, Oliveira e Arantes, 2012).

A criação da SGTES coincide com a movimentação da Organização Internacional do Trabalho (OIT) pela promoção do 'trabalho decente's e com pressões do Ministério Público sobre o governo brasileiro pela regularização de situações ilegais de emprego dentro do SUS. Dentre as principais ações desenvolvidas nesse sentido, destacam-se o Programa Nacional de Desprecarização do Trabalho em Saúde (DesprecarizaSUS), a elaboração do Plano de Carreiras, Cargos e Salários do SUS (PCCS-SUS), a instauração de uma Agenda Nacional do Trabalho Decente no SUS (ANTD-SUS) e a reinstalação da Mesa Nacional de Negociação Permanente do SUS (MNNP-SUS), a última com a finalidade de promover a democratização das relações de trabalho dentro dos serviços públicos de saúde. No entanto, há um arrefecimento das ações dessa natureza a partir do ano de 2007, quando se percebe um redirecionamento da política para a qualificação dos gestores (Teixeira, Oliveira e Arantes, 2012).

Apesar do ensejo de ruptura declarado nos documentos que inauguram a política de gestão do trabalho no âmbito da SGTES (Brasil, 2003 e 2004a), um olhar histórico e transversal dos processos que tangenciam o tema revela significativas continuidades com o momento anterior. Uma delas é que, paralelo ao combate das formas precárias de vínculo encontradas no SUS, houve expansão da publicização e terceirização das atividades, fenômeno amplamente discutido como um dos principais causadores da perda de direitos e piora das condições de trabalho na saúde durante a década de 1990. 


\section{Novos referenciais para o trabalho em saúde}

No início dos anos 2000, uma política de gestão do trabalho em saúde foi esboçada com a responsabilidade de sanar problemas relativos a precarização, ilegalidade e desregulamentação do trabalho no SUS (Brasil, 2003). Mais do que isso, os referenciais trazidos por duas das principais frentes do período, a Política Nacional de Educação Permanente em Saúde (2004c) e a Política Nacional de Humanização (2004b), colocaram o trabalhador em uma nova posição dentro do sistema. No âmbito da SGTES, a imagem desse ator passa a ser construída como sujeito e agente transformador das práticas em saúde, e não apenas como mero recurso humano realizador de tarefas preestabelecidas. Assim, o seu vínculo com a população e com os serviços deveria ser reforçado e sua autonomia e capacidade de intervenção, desenvolvidas.

Ademais de ressaltar os problemas referentes à contratação de profissionais do SUS e à sua fixação, a Norma Operacional Básica de Recursos Humanos (NOB-RH), de 2002, expressou perspectivas consideradas inovadoras para o trabalho em saúde (Brasil, 2002). Ao lado das orientações para a regularização e a desprecarização das situações de emprego, foram apresentadas soluções para os problemas da gestão do trabalho que, de forma declarada, estão relacionadas ao domínio da micropolítica do trabalho vivo em ato na saúde (Merhy, 1997). Nessa perspectiva, o SUS, como instituição, passa a ser considerado um local privilegiado de produção de subjetividades, passível de transformação e instrumento para a realização de desejos coletivos (Cunha e Campos, 2010).

A NOB-RH ressalta ainda que a mudança efetiva no modelo e na qualidade da atenção só poderia ser conquistada no cotidiano da sociedade e dos serviços. A III Conferência Nacional de Gestão do Trabalho e da Educação na Saúde, realizada em 2003, traz a crença nas transformações das práticas de gestão e na afirmação de ações de cuidado democráticas e participativas (Brasil, 2003). As formulações do Ministério da Saúde reafirmam os princípios de universalidade, integralidade, equidade e participação social que estiveram presentes na criação do SUS, e, como categorias intermediárias, são trazidas para o centro da discussão as diretrizes de acolhimento, vínculo, gestão participativa e cogestão.

Enquanto os registros da década de 1980 e 1990 (Brasil, 1986 e 1993) destacam a escassez de profissionais de nível médio, a condição precária da formação e a ausência de qualificação específica encontrada nos serviços, o documento da III Conferência Nacional de Gestão do Trabalho e da Educação na Saúde afirma que a atualização técnico-científica é apenas um dos aspectos necessário à transformação das práticas de saúde, não sendo o seu foco central. O período é marcado pela ênfase no desenvolvimento de qualidades 
no trabalho em detrimento da formação técnica obtida por meio da educação formal.

O avanço na conquista de uma atenção integral à saúde aconteceria, então, a partir da construção coletiva da decisão política de usuários, trabalhadores, prestadores de serviços e gestores. Para os gestores, caberia a elaboração e a execução de ações programáticas e estratégicas que contemplassem as dimensões técnicas, humanas e éticas do trabalho, e que fossem capazes de promover novas relações e governabilidade. Dos trabalhadores, passou a ser exigida maior capacidade de análise e de intervenção nas atividades desenvolvidas.

Nesse contexto, passa a ser defendida a cogestão, e o trabalho em equipe é apontado como a forma legítima do trabalho em saúde, uma vez que seria capaz de contribuir para o arranjo horizontal das responsabilidades profissionais e gerenciais. A premissa de que o cotidiano dos serviços de saúde está em constante transformação é um dos pressupostos que sustentam essa perspectiva, e aparece em consonância com o ideário que paira sobre a produção industrial no padrão flexível. A tarefa da cogestão no SUS seria a de viabilizar contratos e compromissos entre os atores, sempre provisórios e sujeitos a revisão acordada da equipe.

Também é importante ressaltar que, desde 2003, destaca-se um esforço por parte do Ministério da Saúde em reconectar as práticas do SUS com os princípios da integralidade e da participação social. A noção de integralidade que a define como um conjunto articulado de ações e serviços de saúde nos diferentes níveis de complexidade do sistema é ampliada, e também passa a ser relacionada a uma resposta ao sofrimento do paciente que vai além do sistema biológico. Na nova concepção, o alcance da integralidade implica o diálogo, a fim reconhecer as demandas não explícitas das necessidades de saúde dos cidadãos, e a 'horizontalização', para que seja superada a fragmentação das atividades no interior das unidades de saúde (Pinheiro, 2009).

A instauração de um novo paradigma para o trabalho em saúde tem como objetivos a superação das barreiras existentes entre os sujeitos e os campos envolvidos no processo de cuidado - seja entre as diferentes ocupações e disciplinas, seja entre gestores, trabalhadores e usuários; e a maior aproximação dos trabalhadores e serviços às necessidades reais da população. Para tal, surgem como demandas a transformação da cultura relacional antes verificada no sistema e a construção de espaços coletivos de produção do conhecimento em saúde. É nesse contexto que a Política Nacional de Humanização em Saúde e a Política Nacional de Educação Permanente em Saúde ganham centralidade. 


\section{A Política Nacional de Humanização}

A HumanizaSUS é discutida pelo Ministério da Saúde como um conjunto articulado de princípios, diretrizes e método no ano de 2003. No entanto, desde a década de 1990, ações empreendidas pela gestão já se apropriavam do termo "humanização" no sentido de promover a ideia de dignidade e respeito à vida humana e de ética na relação entre pacientes e profissionais (Vaitsman e Andrade, 2005). Progressivamente, a condição dos trabalhadores do SUS foi incorporada ao debate e, a partir dos anos 2000, eles passam a ser considerados, ao mesmo tempo, agentes e instrumentos da melhoria da qualidade da atenção à saúde.

Segundo o texto que marca a sua criação, a HumanizaSUS surge com o intuito de colocar em prática os princípios do SUS por meio da produção de mudanças no modo de gerir e cuidar (Brasil, 2004b). Nesse processo, seria necessária a construção de relações entre usuários e trabalhadores capazes de traçar estratégias coletivas de enfrentamento às relações de poder presentes no sistema. De acordo com Pereira eBarros (2009), o conceito de humanização surge nesse contexto, menos como uma revalorização da imagem de homem, e mais como uma incitação à produção de novos territórios existenciais. O SUS deveria considerar, então, os atores envolvidos no cuidado, em sua capacidade criadora e singular.

De forma sistematizada, a política traz como método a aposta na inclusão de trabalhadores, usuários e gestores na produção e gestão do cuidado e nos processos de trabalho, mediante as rodas de conversa e o incentivo às redes de movimentos sociais e à gestão de conflitos. Como princípios, define: a transversalidade - deve estar presente em todas as políticas e programas do SUS; a indissociabilidade entre atenção e gestão - as decisões da gestão interferem diretamente na atenção; e o protagonismo, a corresponsabilidade e a autonomia dos sujeitos - as mudanças só ocorrem efetivamente quando partem da vontade das pessoas envolvidas. Dentre as principais orientações para a sua concretização são mencionadas as diretrizes de acolhimento para com o usuário, a gestão participativa e a cogestão, e a valorização do trabalhador.

Durante os anos 2000, a humanização da atenção no SUS passa a ser relacionada a um processo de subjetivação, no qual existiria a produção de novos sujeitos no cotidiano dos serviços implicados na realização de novas práticas, por eles idealizadas de forma coletiva. Nesse sentido, a natureza iminentemente conversacional do trabalho em saúde é posta em destaque (Teixeira, Oliveira e Arantes, 2012). A produção de afetos e a qualificação do diálogo passam a ser vistas como elementos fundamentais para a troca de saberes, tirando os diferentes sujeitos do isolamento e das relações de poder hierarquizadas. 


\section{A Política Nacional de Educação Permanente em Saúde}

A HumanizaSUS é criada sob responsabilidade da Secretaria de Atenção à Saúde (SAS). Contudo, dada a sua proposta reformista e seu princípio de transversalidade, verifica-se a difusão de suas diretrizes para os diferentes espaços do SUS. Mais do que zonas transversais, a gestão do trabalho em saúde e a Pneps, ambas sob controle da SGTES, constituem-se oficialmente como eixos estratégicos para a humanização (Brasil, 2004b).

A Pneps é desenvolvida sob o encargo do Departamento de Gestão da Educação na Saúde; no entanto, gestores e autores destacam o seu caráter multilateral, conformando-se, ao mesmo tempo, como uma política de formação e qualificação de profissionais da saúde e de gestão do trabalho. Dessa forma, a análise de seus pressupostos e a história de seu desenvolvimento constituem rico substrato para a compreensão do trabalho no SUS durante os anos 2000.

A Pneps está apoiada no que Ceccim e Feuerwerker (2004) chamam de quadrilátero da formação - ensino-gestão-atenção-participação social -, e se configura como uma política de educação e um processo de ensino-aprendizagem (Ceccim e Ferla, 2009). Tem como bases os conceitos de ensino problematizador (aprendizado inserido de maneira crítica na realidade e sem superioridade do educador em relação ao educando) e de aprendizagem significativa (interessada nas experiências anteriores e nas vivências pessoais dos alunos). Dessa forma, possui como objetivo a produção de conhecimento e de novas formas de trabalhar no cotidiano das instituições de saúde, tendo como ponto de partida a realidade vivida pelos atores envolvidos no dia a dia e as suas experiências como base de interrogação e mudança.

Na política de educação permanente, a participação popular é incorporada ao processo, reafirmando a diretriz do controle social na gestão do SUS. Parte-se do pressuposto de que o quadrilátero ensino-gestão-atenção- participação social é capaz de fomentar a articulação entre educação, trabalho e cidadania. Na mesma mão da política de humanização, a Pneps traz a crença na produção coletiva de saberes e práticas. De forma sintetizadora, ela pode ser definida como centrada no processo de trabalho, não restringida às categorias profissionais, e capaz de promover a autonomia e a responsabilização das equipes de trabalho com base no dia-gnóstico e na busca por soluções compartilhadas. No plano da qualificação dos trabalhadores, a Pneps promoveria o acesso a novos conhecimentos e competências culturais, ligadas às mudanças em curso no mundo do trabalho e ao contexto real das práticas em saúde. 


\section{A qualificação do técnico de enfermagem e as mudanças em curso no trabalho em saúde}

Considero como "técnico de enfermagem" os trabalhadores de nível técnico em saúde, certificados como auxiliares e técnicos, com escolaridade fundamental e média, que integram as equipes de enfermagem nos serviços de saúde no Brasil. Segundo dados do Conselho Federal de Enfermagem (Conselho Federal de Enfermagem, 2013), no ano de 2011, os trabalhadores da enfermagem estavam divididos da seguinte forma: 45,5\% técnicos; 33,09\% auxiliares; $20,46 \%$ enfermeiros de nível superior; e 0,93\% atendentes. Os números evidenciam, portanto, que são os auxiliares e técnicos de enfermagem a grande massa de trabalhadores da saúde, representando $78,59 \%$ da força de trabalho em enfermagem.

Para analisar a reconfiguração da qualificação desse grupo no contexto das mudanças em curso para o trabalho em saúde, escolhi como referencial o conceito de qualificação do trabalho que define essa qualificação como uma relação social (Tartuce, 2004). Nessa perspectiva, a qualificação é uma noção situada no espaço e no tempo, tendo qualquer sociedade os seus critérios próprios para definir e julgar o que é um trabalho qualificado. A qualificação opera como um conceito explicativo que deverá dar conta dos diferentes elementos presentes no contexto das relações de trabalho - e, ao mesmo tempo, considerar esses elementos na análise. Nessa teia, destacam-se como aspectos significativos a história da ocupação; 6 a regulação social e técnica do trabalho; as relações de poder entre capital e trabalho; e a articulação entre estratégias empresariais e individuais dos trabalhadores.

Desde os tempos coloniais, a assistência médico-hospitalar brasileira fora organizada em torno das instituições vinculadas à Igreja, às Santas Casas de Misericórdia e aos hospitais filantrópicos. Nessas instituições, submetido ao controle médico, o cuidado era prestado por pessoal sem qualificação e, geralmente, não remunerado. A profissionalização da enfermagem no Brasil data da década de 1920, com a fundação da Escola de Enfermagem Anna Nery, que nasce no interior de um hospital e submetida ao controle do Departamento Nacional de Saúde Pública.

Para além da determinação das relações sociais de sexo (Kergoat, 1996), que define socialmente o trabalho do cuidado para o âmbito do privado e das atividades realizadas pelas mulheres - fator que dada a configuração das relações sociais na sociedade capitalista confere um status de inferioridade a essa atividade -, a equipe de enfermagem moderna já nasce marcada pela divisão técnica do trabalho relacionada a um recorte de classe. Isso porque a Escola de Enfermagem Anna Nery exigia como pré-requisito para o ingresso de suas alunas o diploma do curso normal, o que pode ser considerado um 
marcador de diferença social no período e que mantinha afastada da instituição a grande maioria de trabalhadoras que já estavam no serviço.

Na década de 1930, com a tendência ao assalariamento e com a aproximação de paradigmas técnico-científicos oriundos do modelo fordista de produção, surge uma tímida preocupação institucional com a falta de qualificação da massa dos trabalhadores responsáveis pelo cuidado que permaneciam sem acesso às instituições de ensino. No entanto, a formação do grupo continuou precária, sendo restrita ao treinamento em serviço e às exigências de saber ler e escrever.

Durante duas décadas, portanto, o trabalho em enfermagem no Brasil esteve organizado a partir da dicotomia entre enfermeiros - detentores do conhecimento e responsáveis pelo trabalho complexo - e práticos de enfermagem - responsáveis pelo exercício de atividades padronizadas e de baixa complexidade. Somente nos anos de 1940, em meio à conjuntura social de expansão da medicina previdenciária e de um ideário modernizador, são criados os primeiros cursos de auxiliares e técnicos de enfermagem no Brasil.

Nas quatro décadas seguintes, o referencial técnico-científico do fordismo, com suas tarefas parcelarizadas e aprendidas por meio de treinamento em serviço, fez-se presente nas atividades realizadas pelos técnicos de enfermagem nos hospitais. A imagem da enfermeira, que fora construída relacionada à caridade e à figura da mulher, sempre esteve presente e foi reafirmada pelos mecanismos de regulação social do período (Pereira, 2011). Contudo, à atividade passou a ser atribuído um forte traço disciplinar, que deveria ser evidenciado no caráter objetivo e científico das atividades realizadas, apesar das baixas qualificações oferecidas aos técnicos.

Nos anos 1980, esse quadro começa a ser revertido. No bojo no Movimento Sanitário brasileiro, enfermeiras sindicalizadas organizam-se em torno de reivindicações pela qualificação da força de trabalho em saúde. Desde então, têm sido empreendidos esforços para qualificar em larga escala tanto profissionais que já se encontram em serviço quanto novos ingressados na profissão. A noção ampliada de saúde, na qual entram em jogo os determinantes sociais, implica mudanças nas diretrizes de formação, pela incorporação das dimensões da observação e da escuta ao processo de trabalho. Entretanto, a demanda sempre urgente pela integração entre ensino e serviço na formação em saúde, na qual a aprendizagem por treinamento constitui armadilha, continuou sendo o eixo de estruturação das políticas de formação e de gestão dos trabalhadores ao longo do tempo (Ramos, 2010).

Dessa forma, as novas dimensões apontadas para o trabalho em saúde na política de humanização, pautadas na compreensão global do processo de cuidado e na produção de subjetividades e afetos nas práticas de saúde, geram novas demandas para o trabalho emocional realizado pelos técnicos de enfermagem. Isso porque esses profissionais, ao mesmo tempo em que con- 
tinuam a receber uma formação baseada em tarefas específicas e carente de subsídios para lidar com os embaraços emocionais e psicológicos decorrentes da natureza do trabalho em saúde, passam a receber responsabilidades referentes à capacidade de lidar com as questões subjetivas dos usuários e de estabelecer redes afetivas com os outros atores do sistema.

O olhar sobre a construção da qualificação do trabalho dos técnicos de enfermagem revela determinações em sua conformação relacionadas à divisão social e técnica do trabalho. Tais mediações, marcadas por um recorte de sexo e classe, historicamente têm conferido baixo status social à ocupação e reproduzido no interior dos serviços de saúde as relações de poder presentes na sociedade capitalista. A proposta presente nas atuais políticas de gestão no SUS, que indica mudanças nas diretrizes para a realização do trabalho em saúde e na cultura relacional do sistema, encontra obstáculos no enraizamento dessas relações na própria estrutura social, econômica e política brasileira.

\section{Gestão do trabalho para trabalhadores}

Embora o contexto político tenha sido otimista, e as promessas de transformação das situações do trabalho nos serviços públicos de saúde, ambiciosas, a política de gestão do trabalho formulada pelo Ministério da Saúde nos anos 2000 encontra limites estruturais à sua execução. Como afirmam Chinelli, Lopes e Vieira (2011), o cenário de implantação de políticas no âmbito da gestão do trabalho é paradoxal.

De início, pode-se afirmar que o movimento pela desprecarização do trabalho impulsionado pela SGTES conviveu com a continuidade dos processos de publicização e terceirização das atividades no interior dos hospitais, o que, em consonância com a difusão tecnológica, representa a intensificação da exploração do trabalho dentro dos serviços públicos de saúde.

É possível inferir relações entre as transformações operadas no trabalho no âmbito do SUS e aquelas mais gerais, relacionadas ao novo paradigma produtivo no capitalismo flexível. As diretrizes almejadas pela gestão do SUS nos anos 2000, em que se destacam as ações no sentido de horizontalização e corresponsabilização dos trabalhadores, muito se assemelham à reestruturação pela qual passou a empresa nas últimas décadas. Autores como Deslandes (2004) e Puccini e Cecílio (2004) já alertaram para os limites de uma política de humanização 'para' os trabalhadores, em que essa significaria uma melhoria das condições de trabalho do cuidador. Diante das más condições de trabalho no interior das instituições e da perda de direitos trabalhistas, parece que a esses profissionais são exigidas qualidades de um 'Hércules moral', capaz de carregar todo o peso dos limites estruturais do 
SUS munido apenas de dons relacionados à solidariedade e ao altruísmo, como apontam Chinelli e Vieira (2013).

De fato, o arrefecimento das ações de desprecarização e valorização do trabalho em saúde a partir de meados dos anos 2000 se coloca como obstáculo a uma transformação efetiva na cultura relacional enraizada no SUS. O aumento da responsabilidade e da carga subjetiva do trabalho para os profissionais, quando não acompanhado de ganhos materiais para esses trabalhadores, pode ocasionar piora da sua vida no trabalho. No caso dos técnicos de enfermagem, a neutralização das relações de poder há de passar ainda pelo lugar da educação profissional nas políticas de educação e trabalho da sociedade brasileira. Enquanto a ela for reservado um lugar subalterno, as hierarquias profissionais tão marcadas dentro do SUS continuarão a representar obstáculos à democratização das relações de trabalho e ao fomento da comunicação como forma de humanização.

\section{Considerações finais}

O artigo identificou na história do próprio SUS, em consonância com os movimentos mais gerais entre Estado e capital na sociedade contemporânea, as determinações do trabalho em saúde durante os anos 2000.

A SGTES constituiu-se como um marco para o período, no entanto, a Política Nacional de Humanização e a Política Nacional de Educação Permanente em Saúde se mostraram fortes polos irradiadores de diretrizes para a gestão do trabalho, reconfigurando dinâmicas sociais e impondo novas demandas para a qualificação do trabalho dos técnicos de enfermagem.

Ao final, permitiu-se uma reflexão acerca dos limites impostos pela sociedade capitalista, e pela própria organização do SUS, à transformação do trabalho em saúde. Tornou-se evidente o caráter tênue da linha que separa atualmente empoderamento e autonomia da exploração da subjetividade dos trabalhadores nos serviços públicos de saúde. 
Resumen En este artículo, identifico las determinaciones políticas y sociales que discurren en la gestión del trabajo en el Sistema Único de Salud Brasileño durante los años 2000 y discuto la configuración de la cualificación del trabajo de los técnicos de enfermería con base en documentos oficiales del periodo. El trabajo en el Sistema Único de Salud, en las últimas dos décadas, fue discurrido por dos movimientos centrales: ideales de gestión adoptados por el Estado relacionados a lo paradigma de la administración pública gerencial; y articulación de las especificidades del trabajo en salud, a un solo tiempo, con los principios y directrices definidos para el sistema en la Constitución Federal de 1988 y con los modos de organización del trabajo característicos del estándar de acumulación flexible. La conformación de esos elementos, por su vez, se expresa en las acciones y programas del Ministerio de la Salud como nuevas demandas para el trabajo en salud, que dan énfasis a los aspectos subjetivos, emocionales y relacionales de la actividad.

Palabras clave trabajo en salud; técnicos de enfermería, cualificación del trabajo en salud, gestión del trabajo en salud.

\section{Notas}

1 Universidade Federal do Rio de Janeiro, Programa de Pós-graduação em Sociologia e Antropologia, Rio de Janeiro, Rio de Janeiro, Brasil.

$<$ roberta.coroa@gmail.com>

Correspondência: Rua Jornalista Orlando Dantas, $n^{\circ}$ 301, ap. 04, CEP 22231-010, Rio de Janeiro, Rio de Janeiro, Brasil.

2 A chamada visão 'relativista' é representada inicialmente por Pierre Naville em oposição à visão 'substancialista', que toma a qualidade do trabalho para determinar diretamente a qualificação, o que lhe confere um caráter 'essencial' ou 'substancial' (Tartuce, 2004).

3 Cuja proposta básica é flexibilizar a administração pública e aumentar a accountability ou responsabilização governamental (CLAD, 1998).

$4 \mathrm{O}$ documento ressaltava a urgência de reorganização da administração pública em todos os níveis e sinalizava a necessidade de incorporação da gestão participativa e da gestão pela qualidade total, elevação da produtividade, flexibilidade das relações de trabalho, diferenciação da remuneração e processo permanente de negociação coletiva do trabalho (Santana, 1994).

5 No Brasil, a promoção do Trabalho Decente passou a ser um compromisso assumido entre o Governo brasileiro e a OIT a partir de junho de 2003, com a assinatura, pelo presidente da República, Luiz Inácio Lula da Silva, e pelo diretor-geral da OIT, Juan Somavía, do memorando de entendimento que prevê o estabelecimento de um Programa Especial de Cooperação Técnica para a Promoção de uma Agenda Nacional de Trabalho Decente, em consulta às organizações de empregadores e de trabalhadores. Ver: http://portal.mte.gov.br/antd/a,genda-nacional-de-trabalho-decente-antd.htm.

6 Para a pesquisa histórica acerca da constituição da categoria técnico de enfermagem, utilizei-me de Lima, 2010. 


\section{Referências}

BRASIL. Constituição da República Federativa do Brasil de 1988. Presidência da República, 1988.Disponível em: ttp://www.planal to.gov.br/ccivil_03/constituica/constituicao compilado.htm>. Acesso em: 8 maio 2014 .

BRASIL. Ministério da Administração Reforma do Estado. Plano diretor da reforma do aparelho do Estado. Brasília: MARE, 1995.

BRASIL. Ministério da Administração Federal e Reforma do Estado. Programa da qualidade e participação na administração pública / Ministério da Administração Federal e Reforma do Estado: Brasília: MARE, 1997.

BRASIL. Ministério da Saúde. Conferência Nacional de Recursos Humanos para a Saúde. Brasília: Ministério da Saúde, 1986. Relatório Final.

BRASIL. Ministério da Saúde. Conferência Nacional de Recursos Humanos, 2. Brasília: Ministério da Saúde, 1993. Relatório final.

BRASIL. Ministério da Saúde. Conferência Nacional de Gestão do Trabalho e da Educação na Saúde, 3. Brasília: Ministério da Saúde, 2003. Relatório final.

BRASIL. Ministério da Saúde. Gestão do trabalho e da regulação profissional em saúde agenda positiva do Departamento de Gestão e da Regulação do Trabalho em Saúde. Brasília: Ministério da Saúde, 2004.

BRASIL. Ministério da Saúde. Portaria $\mathrm{n}^{\circ}$ 198/GM/MS, de 13 de fevereiro de 2004. Brasília, v. 141, n. 32, 2004. Seção 1, p. 3741.

BRASIL. Ministério da Saúde. HumanizaSUS: política nacional de humanização: a humanização como eixo norteador das práticas de atenção e gestão em todas as instâncias do SUS. Brasília: Ministério da Saúde, 2004.
BRASIL. Ministério da Saúde. Norma operacional básica de recursos humanos NOB/ RH-SUS:Apresentação da quarta versão Brasília: Ministério da Saúde, 2002.

VIDAL, Audrey. Caderno Espaço Feminino, Uberlândia, v. 24, n. 1, p. 49-77, jan./jun. 2011.

BRESSER-PEREIRA, Luiz C. “Da administração pública burocrática à gerencial". Revista do Serviço Público, Brasília, v. 47, n. 1, jan. 1996a.

CECCIM Ricardo B.; FERLA, Alcindo A. Educação Permanente em Saúde. In: PEREIRA, Isabel B.; LIMA, Julio C. F. (Org.). Dicionário da educação profissional em saúde. Rio de Janeiro: Escola Politécnica de Saúde Joaquim Venâncio, 2009. p.162-167.

CECCIM Ricardo B.; FEUERWERKER, Laura C. M. O quadrilátero da formação para a área da saúde: ensino, gestão, atenção e controle social. Physis: Revista de Saúde Coletiva, Rio de Janeiro, v. 14, n. 1, p. 41-66, 2004.

CHINELLI, Filippina; LACERDA, Alda; VIEIRA, Monica. A reconfiguração gerencial do Estado brasileiro e os trabalhadores da saúde nos anos 1990. In: DURÃO, Anna V.; LOPEZ, Marcia; VIEIRA, Monica (Org.). Para além da comunidade: trabalho e qualificação dos agentes comunitários de saúde. Rio de Janeiro: Escola Politécnica de Saúde Joaquim Venâncio, 2011. p. 33-78.

CHINELLI, Filippina; VIEIRA, Monica. Relação contemporânea entre trabalho, qualificação e reconhecimento: repercussões sobre os trabalhadores técnicos do SUS. Trabalho, Educação e Saúde: tendências e perspectivas. Ciência \& Saúde Coletiva, Rio de Janeiro, v.18, n.6, p. 1591-1600, jun. 2013. 
CHINELLI, Filippina; LOPES, Marcia; VIEIRA, Monica. O trabalho e a educação na saúde: a questão dos recursos. In: DURÃO, Anna V.; LOPES, Marcia; VIEIRA, Monica (Org.). Para além da comunidade: trabalho e qualificação dos agentes comunitários de saúde. Rio de Janeiro: Escola Politécnica de Saúde Joaquim Venâncio, 2011. p.79-118.

CLAD. A New Public Management for Latin America. Caracas: CLAD - Centro Latinoamericano de Administración para el Desarrollo, 1998.

\section{CONSELHO FEDERAL DE ENFERMAGEM.}

Análise de dados das inscrições dos profissionais de Enfermagem existentes nos Conselhos Regionais no ano de 2011. Brasília, 2013. Disponível em: <http://www.portalcofen. gov.br/atlas/> . Acesso em: 29 maio 2014.

CUNHA, Gustavo T.; CAMPOS, Gastão W. S. Método Paidéia Para Co-gestão de Coletivos Organizados Para o Trabalho. Org \& demo, Marília, v.11, n.1, p. 31-46, jan./jun., 2010. Disponível em: $<$ http://www2.marilia.unesp. br/revistas/index.php/orgdemo/article/view File/468/364> . Acesso em: 8 maio 2014.

DEDDECA, Claudio S. O trabalho no setor saúde. São Paulo em Perspectiva, São Paulo, v. 22, n. 2, p. $87-103,2008$

DESLANDES, Suely F. Análise do discurso oficial sobre a humanização da assistência hospitalar. Ciência \& Saúde Coletiva, Rio de Janeiro, v. 9, n. 1, p. 7-14, 2004

GIDDENS, Anthony. A terceira via: reflexões sobre o impasse político atual e o futuro da social-democracia. Rio de Janeiro: Editora Record, 1995.

KERGOAT, Danièle. Relações sociais de sexo e divisão sexual do trabalho. In: LOPES, Marta J. M.; MEYER, Dagmar E.; WALDOW, Vera R. (Org.) Gênero e saúde. Porto Alegre: Artes Médicas, 1996. p.19-27.

LIMA, Julio C. F. Politica de saúde e formação profissional dos trabalhadores técnicos de enfermagem. 469 f. 2010. Tese
(Doutorado em Educação) - Universidade do Estado do Rio de Janeiro, Faculdade de Educação, Rio de Janeiro, 2010.

MACHADO, Maria H. Gestão do Trabalho em Saúde. In: PEREIRA, Isabel B.; LIMA, Julio C. F. (Org.). Dicionário da educação profissional em saúde. Rio de Janeiro: Escola Politécnica de Saúde Joaquim Venâncio, 2009. p.227-230

MARTINS, Maria I. C.; MOLINARO, Alex. Reestruturação produtiva e seu impacto nas relações de trabalho nos serviços públicos de saúde no Brasil. Ciência \& Saúde Coletiva, Rio de Janeiro, v.18, n.6, p. 1667-1676, 2013. Disponível em: <http://www.scielosp .org/pdf/csc/v18n6/18.pdf>. Acesso em: 8 maio 2014.

MERHY, Emerson E. Em busca do tempo perdido: a micropolítica do trabalho vivo em saúde. In: MERHY, Emerson E.; ONOCKO, Rosana (Org.) Agir em Saúde: um desafio para o público. São Paulo: Hucitec, 1997. p. 71-112.

MERHY, Emerson E.; FRANCO, Túlio B. Trabalho em Saúde. In: PEREIRA, Isabel Brasil; LIMA, Julio C. F. (Org.). Dicionário da educação profissional em saúde. Rio de Janeiro: Escola Politécnica de Saúde Joaquim Venâncio, 2009. p. 427-432.

PARTIDO DOS TRABALHADORES. Programa de governo 2002 coligação Lula presidente: um Brasil para todos. São Paulo, 2002. Disponível em: <http://novo.fpabra mo.org.br/uploads/programagoverno.pdf $>$. Acesso em: 22 jul. 2016.

PEREIRA, Audrey V. Relações de gênero no trabalho: reflexões a partir de imagens construídas de enfermeiras e enfermeiro. Caderno Espaço Feminino, Uberlândia, v. 24, n. 1, p. 49-77, jan./jun. 2011.

PEREIRA, Eduardo H. P; BARROS, Regina. D. B. Humanização. In: PEREIRA, Isabel B.; LIMA, Julio C. F. (Org.). Dicionário da educação profissional em saúde. Rio de Janeiro: Escola Politécnica de Saúde Joaquim Venâncio, 2009. p. 243-247. 
PINHEIRO, Roseni. Integralidade em Saúde. In: PEREIRA, Isabel B.; LIMA, Julio C. F. (Org.). Dicionário da educação profissional em saúde. Rio de Janeiro: Escola Politécnica de Saúde Joaquim Venâncio, 2009.p.255-262.

PIRES, Denise. Reestruturação produtiva e trabalho em saúde no Brasil. São Paulo: Editora Annablume, 2008.

PUCCINI, Paulo T.; CECÍLIO, Luiz C. O. A humanização dos serviços e o direito à saúde. Cadernos de Saúde Pública, Rio de Janeiro, v. 20, n. 5, p. 1342-1353, 2004.

RAMOS, Marise N. Trabalho, educação e correntes pedagógicas no Brasil: um estudo a partir da formação dos trabalhadores técnicos da saúde. Rio de Janeiro: Escola Politécnica de Saúde Joaquim Venâncio, 2010.

SANTANA, José P. (Org.). Perspectivas para a gestão do trabalho no Sistema Único de Saúde. Brasília: Opas, 1994. Disponível em: $<$ http://bvsms.saude.gov.br/bvs/publicaco es/0116conf_rh.pdf $>$. Acesso em: 8 maio 2014.
TARTUCE, Gisela L. B. P. Algumas reflexões sobre a qualificação do trabalho a partir da sociologia francesa do pós-guerra. Educação e Sociedade, Campinas, vol. 25, n. 87, p. 353382, 2004. Disponível em: http://www. scielo.br/pdf/es/v25n87/21461.pdf >. Acesso em: 28 maio 2014.

TEIXEIRA, Marcia; OLIVEIRA, Roberta O.G.; ARANTES, Rosana F. Mudanças nas Políticas do Trabalho e da Educação em Saúde no Governo Lula. In: MACHADO, Cristiani V.; BAPTISTA, Tatiana W. F.; LIMA, Luciana D. Politicas de Saúde no Brasil: continuidades e mudanças. Rio de Janeiro: Editora Fiocruz, 2012. p.197-225.

VAITSMAN, Jeni; ANDRADE, Gabriela. Satisfação e responsividade: formas de medir a qualidade e a humanização da assistência à saúde. Ciência \& Saúde Coletiva, v. 10, n. 3, p. 599-613, 2005.

VARELLA, Thereza C.; PIERANTONI, Célia R. Mercado de trabalho: revendo conceitos e aproximando o campo da saúde: a década de 90 em destaque. Physis: Revista de Saúde Coletiva, Rio de Janeiro, v. 18, n. 3, p.521544, 2008. Disponível em: $<$ http://www. scielo.br/pdf/physis/v18n3/v18n3a09>.

Acesso em: 28 maio 2014.

Recebido em 29/07/2014

Aprovado em 20/10/2014 